\title{
Study on Efficiency of the Sewage Treatment Plant at College Campus (Karnataka) for Sustainable Artificial Recharge Designed model: A Case study
}

D.O.I - 10.51201/Jusst12575

http://doi.org/10.51201/Jusst12575

\author{
Dhanraj M R ${ }^{1}$, A Ganesha ${ }^{2}$ \\ International Center for Applied science, MAHE Manipal ${ }^{1}$ \\ International Center for Applied science, MAHE Manipal ${ }^{2}$
}

\begin{abstract}
The aim of this study is to evaluate the quality of sewage generated from 7000 KLD Sewage Treatment Plant (STP) located at Manipal Institute of Technology, Manipal Karnataka which is based on the Activated Sludge Technology. The study of sewage quality of this plant is essential as most of the treated effluent discharged into a stream during monsoon and remaining season used for a Gardening purpose. Water samples were collected from the outlet and analyzed for the major wastewater quality parameters, such as $\mathrm{pH}$, Biochemical Oxygen Demand (BOD) and residual chlorine. The overall quality of sewage of 7000 KLD Sewage treatment plants will be evaluated by collecting samples. The results of these evaluations also determine whether the effluent discharged into the water body is under limits given by Karnataka state pollution control board (KSPCB) \& BIS standards.
\end{abstract}

Keywords: Biochemical oxygen demand, total dissolved solids, residual chlorine, pH.

\section{Highlights}

- A program refocused on treatment systems \& disposal methods.

- A systemic approach to management that can guide sustainable development \& handling of treated sewage.

- Monitoring and handling of treated sewage, its issues faced by private treatment bodies.

\section{INTRODUCTION}

Due to rapid urbanization and smart city program from the government, the focus is to drive sustainability. A systematic way to attain sustainability in the present scenario is very important for a drastic change, due to the climate change factors and deforestation (CPCB, India). There are many forms of disposal of treated sewage available in India, but presently it has been used as a source for processing in the industry, used in civil engineering and as well as for the landscapes, irrigation purposes. The main 
objective of the study is to assess the quality of the STP and compare the results with the existing disposal standards prescribed by the Karnataka state pollution control board, KSPCB.

\subsection{Theoretical underpinnings}

\section{Opportunities for wastewater treatment}

Today urban wastewater management has become a pressing problem globally. Historically, traditionally, centralized systems such as activated sludge process (ASP), Membrane bio-reactor (MBR), Sequential batch reactor (SBR) have been used in most of the sewage treatment systems. The improper management of domestic sewage in the southern region presents a major problem. The cumulative management of treated wastewater is also a major problem of disposal. The existing technology for the treatment of wastewater doesn't permit the reuse for drinking but certainly permits for disposal as per Indian standards (IS Environmental protection 1986 with an amendment on 1993). A study was conducted in Patiala City, Punjab (India) by developing a conceptual model to overcome the problem of water in the city by sustainable water management thereby, segregating the grey water \& black water and along with the model for the subwatershed level urban storm \& grey water (Amarpreet Singh Arora, 2017). A study conducted on Managed aquifer recharge in Israel by infiltration of desalinated seawater in order to understand the hydrogeological \& geochemistry (Yonatan Ganot et.al. 2017). The purpose of this review is to find the trends that are been already existing for recycle and reuse of treated sewage as per the government-regulated forms. For this reason, only a few articles to reuse of treated domestic sewage is been found.

\subsection{Existing types of disposal facilities in India}

It is obvious that developing nations adopt the methods which have been authenticated scientifically from foreign nations. Although we have different methods of disposal after the sophisticated treatment as per the guidelines of standards from CPCB/WHO. There are different types of treatment systems adopted in India as per the treatment quality or standards by the government of India. Wastewater reuse in 
agriculture would be an attractive proposition to overcome the water shortage. The intensifying of the reuse of treated sewage can be enhanced by mixing the irrigation water with the wastewater by subsurface drip irrigation will possibly enhance the reuse (Tyagi et.al).

\section{Treatment flowchart}

\section{Fig: 1}

Water treatment components

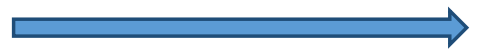

Treatment flowchart

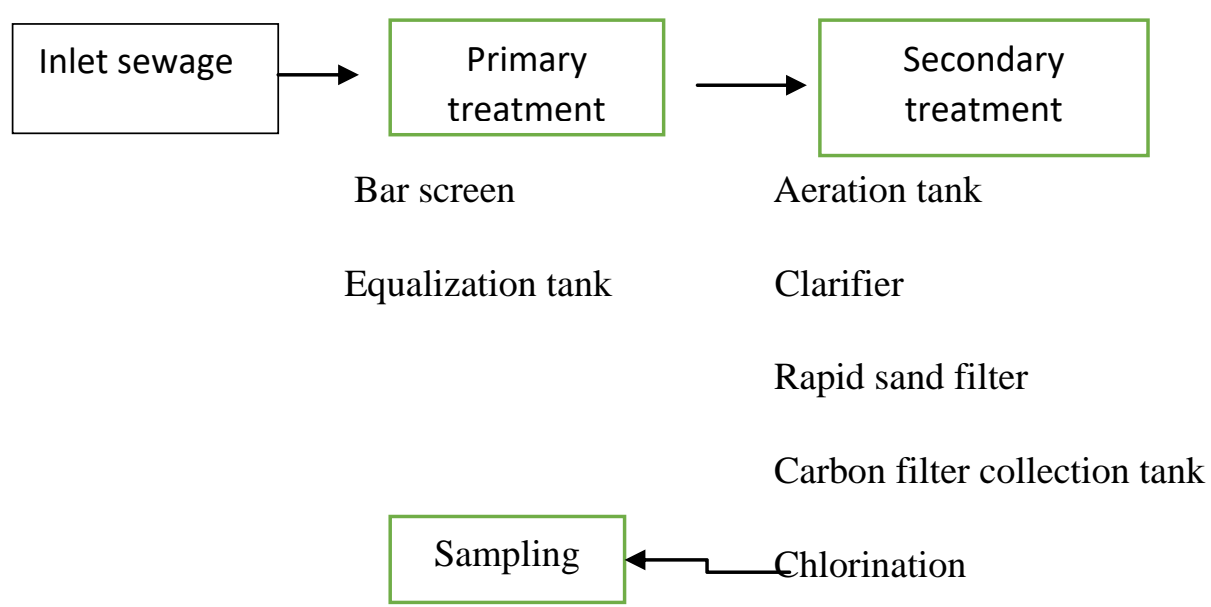

\section{Methodology:}

One-year quality assessment study is being conducted for the existing sewage treatment plant located at Manipal Institute of Technology, Manipal. Samples were collected from the inlet and outlet of the Sewage treatment plant from January 2018 to December 2018. Collected samples were analyzed immediately after the collection for $\mathrm{pH}$. Suspended solids, BOD, residual chlorine in the laboratory by the standard procedure as per Indian Standards 10500:2001. The results obtained after analyses from raw wastewater \& final treated wastewater is been compared with Indian disposal standards. 


\section{Observation \& Result}

Samples were collected during a period of one year and were tested in the laboratory for four wastewater quality parameter $\mathrm{pH}, \mathrm{BOD}$, oil \& grease, Residual Chlorine. The discharge standards are stipulated as per section 17(1)(g) of the water (Preservation and control of pollution) Act, 1974.

Table no. 1 listed test observations of wastewater quality parameters taken at Inlet and Outlet. The pH values of the treated outlet observed between 6.1 to 7.5 which are within the permissible limits as per KSPCB. (KSPCB Limit: 6.5 -9). BOD values of the treated outlet are between $5 \mathrm{mg} / \mathrm{L}$ to $8.6 \mathrm{mg} / \mathrm{L}$ which are within the permissible limits of KSPCB. (KSPCB limit must be <10). the result of the physicochemical analysis and bacteriological enumerations of the peak and nonpeak hours of the inlet and outlet from the STP are presented.

\section{Methods of experiment adopted}

$\mathrm{pH}-$ Electro metric method $\mathrm{pH}$ meter

Suspended solids- Evaporation method

Oil \&grease-Separating funnel method

BOD 5 days@20 c - Dilution method

Residual chlorine - Colorimetric method

Sl.no BIS standards of disposal

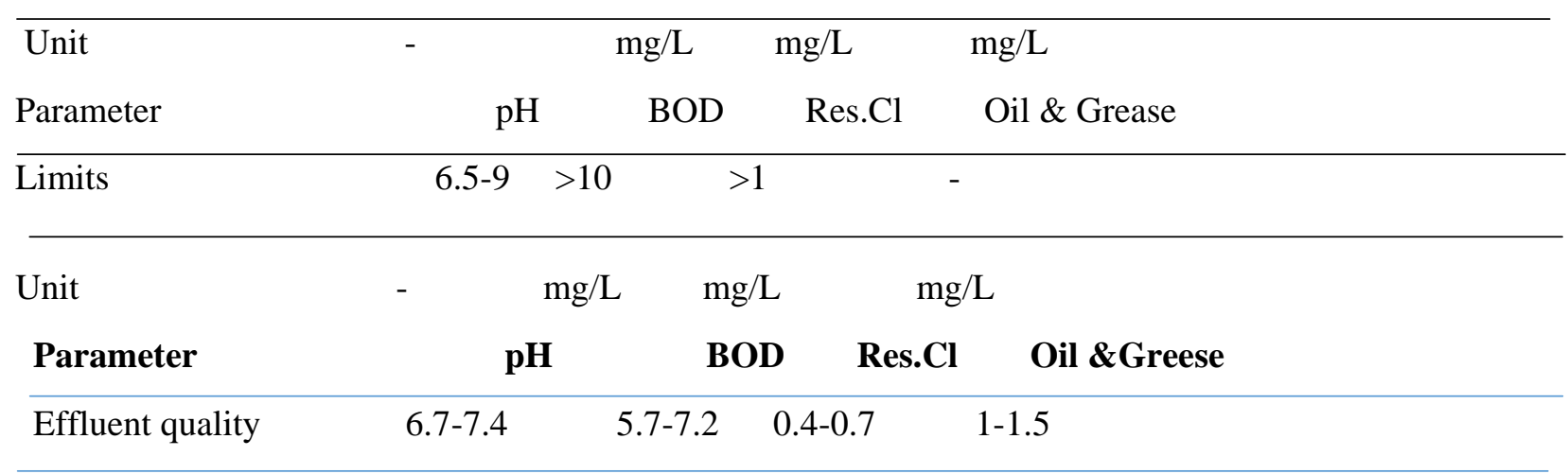

Figure 1 shows the variation of BOD, TSS, pH, residual chlorine at Influent. The maximum value of BOD at the inlet is 140 and the minimum value is 100 . The maximum value of COD at the inlet is 272 
and the minimum value is 214 . The maximum value of TSS at the inlet is 182 and the minimum value is 151.

\section{Statistical analysis}

pH and $B O D$

The $\mathrm{pH}$ value is determined by Electrometric $\mathrm{pH}$ meter. The Pearson correlation coefficient is used to measure the strength of a linear association between two variables, where the value $r=1$ means a perfect positive correlation and the value $\mathrm{r}=-1$ means a perfect negative correlation.

$$
r=\frac{\sum_{i}\left(x_{i}-\bar{x}\right)\left(y_{i}-\bar{y}\right)}{\sqrt{\sum_{i}\left(x_{i}-\bar{x}\right)^{2}} \sqrt{\sum_{i}\left(y_{i}-\bar{y}\right)^{2}}}
$$

The correlation coefficient between the $\mathrm{pH} \& \mathrm{BOD}$ is found to be weak with a value $\mathrm{r}=-0.2746$.

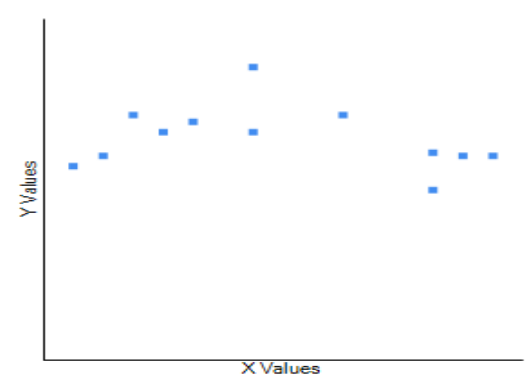

$\mathrm{X}$-axis - $\mathrm{pH}, \mathrm{Y}$-axis - BOD

$B O D$

The Biochemical oxygen demand is determined by the dilution method at $20^{\circ} \mathrm{C}$ for 5 days. It is found that there is a strong correlation between BOD vs BOD, the value of $r=1$. 


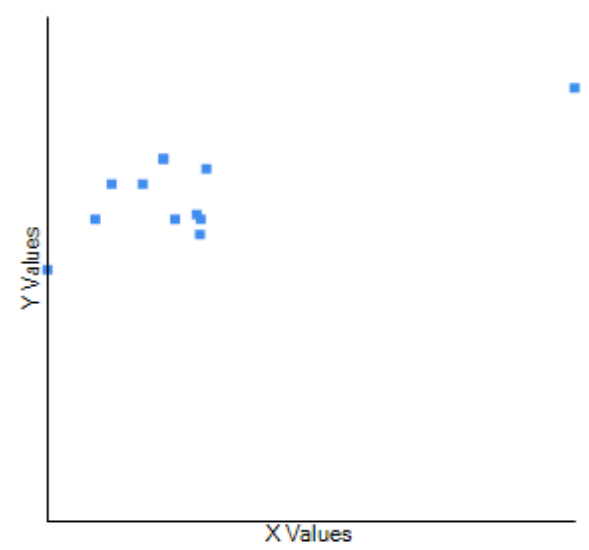

$\mathrm{X}$ value- $\mathrm{BOD}, \mathrm{Y}$ value- BOD

\section{Residual chlorine}

This is determined by the colorimetric method. The relationship between residual chlorine vs BOD is found to be $r=-0.0732$ which indicates poor relationship and there is no influence between these two variables.

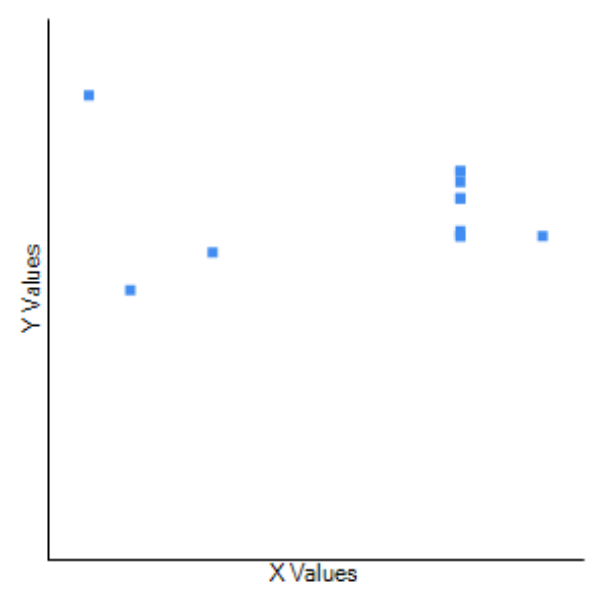

$\mathrm{X}$ value - Res.Cl, Y axis - BOD.

Oil \& grease 
This is determined by separating the funnel method. The relationship between the oil \& grease and BOD is determined the value of $\mathrm{r}=-0.06$. Technically it is found to be a negative relationship between oil grease and BOD.

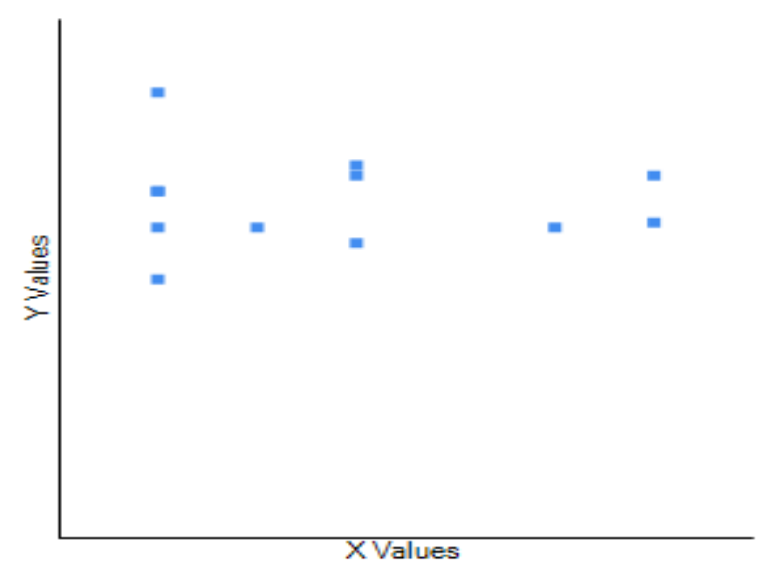

$\mathrm{X}$-axis - oil \& grease, Y-axis - BOD

\section{DISCUSSION}

It's always important to maintain the inflow rate at the sewage treatment plant so that it will not form any disturbance in the next process of treatment. Expectation remarks in the treatment system must not be compromised at any level of treatment to meet the disposal standards. This will enhance the will power to make the study of these kinds. Proper Maintainance and back up of pump place a prominent role in functioning of the system also by this we can overcome the problem of choking. the artificial recharge practice is not an unachievable task it needs a great effort in the maintenance of the sewage treatment plants to simulate the outflow for a proper band of disposal standards as per the government rules \& regulations.

\section{Conclusion}

The treatment efficiency is found to be within the limits of disposal standards. There is no institute in India were the artificial recharge practice is being commissioned. So, therefore, we need firstly a properly controlled setup model to generate the baseline data to avoid future contamination also the pollutant 
transport distance based on geographical location. This can overcome the problem of disposal as well as add on one of the methods of disposal to attain sustainability.

\section{Acknowledgment}

The authors \& co-author are extremely grateful to the director and management for their perpetual support, encouragement, and inspiration along with the excellent library facilities, \& accessible for top indexed journals provided to the authors during the course of this work.

Ethical approval and consent to participate -I am sending this manuscript entitled "Study on Efficiency of the Sewage Treatment Plant at College Campus (Karnataka) For Sustainable Artificial Recharge Designed model: A Case study" authored by Dhanraj \& Ganesha A. This paper is not being published or sent to any publication. This paper is prepared purely by collecting samples and tested in the laboratory for in-depth understanding and the necessity to conduct more research in India, due to the present \& emerging situation for treated water disposal in India. All the data and information provided are real and cited at the reference.

Consent for publication: Author \& Co-Author grant the permission for the publisher to publish this manuscript, after the acceptance for publication.

Conflict of Interest: Author and co-author have no conflict of interest.

Funding: There is no funding available for this project.

Author's contribution: Includes mobilization of the resources, Design of the model and collecting information to enhance the quality of work.

\section{Author's information: Research scholar}

\section{References:}

1. Directions issued by the central pollution control board vide No. A 19014/43/06-MON/709.

2. Environmental (protection) rules 1986. 
3. Amarpreet Singh Arora: Urban stormwater - greywater management system for sustainable urban water management at sub-watershed level, Volume 22, 2017 International Conference on Advances in Energy Systems and Environmental Engineering (ASEE17), 07 November 2017.

4. Ganot, Yonatan et.al -Geochemical processes in a calcareous sandstone aquifer during managed aquifer recharge with desalinated seawater, 19th EGU General Assembly, EGU2017, proceedings from the conference held 23-28 April 2017 in Vienna, Austria., p.1633.

5. R.K.Yadav, B Goyal, R.K Sharma, S.K Dubey, P.S Minhas: Post-irrigation impact of domestic sewage effluent on the composition of soils, crops, and groundwater-A case study, Volume 28, Issue 6, December 2002, Pages 481-486 ( Elsevier). 